\title{
ÉPOCAS DE PLANTIO DA LENTILHA PRECOCE EM QUATRO REGIÕES DE MINAS GERAIS'
}

\author{
ROGÉRIO FARIA VIEIRA², MARIA APARECIDA VILELA DE RESENDE ${ }^{3}$, CLIBAS VIEIRA $^{4}$ e RODRIGO TICLE FERREIRA ${ }^{5}$
}

RESUMO - Foram conduzidos cinco ensaios, todos irrigados, em quatro regiões de Minas Gerais: Viçosa, Leopoldina (Zona da Mata), Patos de Minas (Alto Paranaíba), Uberaba (Triângulo) e Janaúba (Norte), com o objetivo de determinar a melhor época de plantio da lentilha precoce. Em Viçosa, foram estudadas seis datas de plantio, de 15/3 a 30/5; em Leopoldina, quatro, de 7/4 a 10/6; em Uberaba e Patos de Minas, seis, de 17/2 a 2/6; e em Janaúba, cinco, de 16/5 a 3/8. O intervalo entre datas de plantio foi de, aproximadamente, 20 dias. No ensaio de Viçosa, foi utilizada a cultivar Precoz, plantada no espaçamento entre fileiras de $40 \mathrm{~cm}$, com 30 sementes $/ \mathrm{m}$; nos outros ensaios, a Silvina, no espaçamento entre fileiras de $30 \mathrm{~cm}$, com 50 sementes $/ \mathrm{m}$. Em geral, os maiores rendimentos foram alcançados quando o plantio foi feito em maio, principalmente na segunda quinzena. Em Viçosa, a lentilha também teve bom desempenho quando plantada na segunda quinzena de março. Em Leopoldina e Janaúba, os dois locais de temperaturas mais altas, o plantio no início de junho não prejudicou o rendimento, se comparado com o da segunda quinzena de maio. Nas épocas de plantio em que foram obtidos os maiores rendimentos, a lentilha precoce, após a emergência, levou entre 28 e 60 dias para iniciar o florescimento; e da emergência até a colheita, entre 92 e 112 dias. O maior rendimento médio foi alcançado em Leopoldina, quando o plantio foi realizado em 27/5: $1.644 \mathrm{~kg} / \mathrm{ha}$. O peso de 100 sementes da 'Silvina'variou de 5,5 a 6,3 gramas, quando o plantio foi feito em maio.

Termos para indexação: Lens culinaris, ciclo de vida, produtividade.

\section{SOWING DATES FOR EARLY LENTIL CULTIVARS IN FOUR REGIONS OF MINAS GERAIS, BRAZIL}

\begin{abstract}
Trials were conducted in five municipalities of four regions of Minas Gerais State: Viçosa, Leopoldina (Zona da Mata), Patos de Minas (Alto Paranaíba), Uberaba (Triângulo) and Janaúba (Norte), in order to determine the best sowing date for early lentil. In Viçosa, six sowing dates were studied from 15th March to 30th May; in Leopoldina, four, from 7th April to 10th June; in Uberaba and Patos de Minas, six, from 17th February to 2nd June; in Janaúba, five, from 16th May to 3rd August. The interval between sowing dates was approximately 20 days. The cultivar Precoz planted with 30 seeds per meter and $40 \mathrm{~cm}$ between rows was used in the Viçosa trial. The cultivar Silvina with 50 seeds per meter and $30 \mathrm{~cm}$ between rows was used in the other trials. All trials were sprinkler irrigated. In general the highest yields were obtained when lentil was planted in May, particularly in the second half. In Viçosa, lentil also performed well when planted during the second half of March. In Leopoldina and Janaúba, the warmest locations, planting at the beginning of June did not impair lentil yield. From emergence to flowering, lentil took between 28 to 60 days, and from emergence to harvest, between 92 to 112 days, when planted during the best sowing dates. The highest yield was attained at Leopoldina when lentil was planted on 27 May: 1,644 kg/ha. One hundred-seed weight of cultivar Silvina varied from 5.5 to 6.3 grams when lentil was planted in May.
\end{abstract}

Index terms: Lens culinaris, life cycle, yield.

${ }^{1}$ Aceito para publicação em 21 de setembro de 1998. Trabalho financiado pela FAPEMIG.

${ }^{2}$ Eng. Agr., Dr., Embrapa/Epamig, Vila Gianetti, casa 47, CEP 36571-000 Viçosa, MG. E-mail: rfvieira@homenet.com.br

${ }^{3}$ Eng. Agr., M.Sc., Epamig, Rodovia MGT/122, km 155, Caixa Postal 12, CEP 39440-000 Nova Porteirinha, MG.

${ }^{4}$ Eng. Agr., Dr., Dep. de Fitotecnia, UFV, CEP 36571-000

Viçosa, MG. Bolsista do CNPq.

${ }^{5}$ Estudante do curso de Agronomia, UFV.

\section{INTRODUÇÃO}

A lentilha foi, provavelmente, uma das primeiras leguminosas de grão a ser domesticada: a descoberta dessa espécie deu-se em Mureybit, no norte da Síria, no período de 9.500-10.000 antes de Cristo (Hawtin et al., 1980). A lentilha originou-se, provavelmente, no Oriente Próximo e na região mediterrânea (Duke, 1983). 
Em 1995, foram produzidos no mundo 2.813 mil t de grãos, com $75 \%$ da produção concentrada na Ásia, principalmente na Índia (792 mil t) e na Turquia (615 mil t). Fora do continente asiático, o Canadá foi o maior produtor com 426 mil t. A produtividade média da lentilha nesses países foi de 647, 976 e $1.315 \mathrm{~kg} / \mathrm{ha}$, respectivamente (FAO Production Yearbook, 1995). A produção brasileira de lentilha é pequena, fazendo-se necessária a importação para abastecer o mercado interno. O Brasil importou, em 1991, 4.944 t, principalmente do Canadá e da Turquia, o que representou gastos da ordem de US\$ 3.310.985,00 (Brasil, 1992).

A lentilha, cultura de inverno nos trópicos, é plantada desde o nível do mar até $3.800 \mathrm{~m}$ de altitude, e não se adapta aos trópicos úmidos. A temperatura ótima para a germinação das sementes é de $18-21^{\circ} \mathrm{C}$, e, para alto rendimento, situa-se em torno de $24^{\circ} \mathrm{C}$ (Duke, 1983).

A lentilha floresce mais cedo em dias longos, mas sua exigência fotoperiódica varia muito entre cultivares. No International Center for Agricultural Research in the Dry Areas (ICARDA), 36 linhagens de lentilha foram cultivadas em condições de comprimento de dias curtos ( 8 horas), normais (13,3-14,4 horas) e longos (15 horas). Não foram produzidas flores em dias curtos, mas a floração de várias linhagens coincidiu, independentemente do comprimento do dia, se normais ou longos. Isso indica que há uma necessidade qualitativa de dias longos. Outras linhagens, no entanto, exibiram resposta quantitativa, mas de grau variável: redução de três a 21 dias do início da floração em condições de dias longos, quando em comparação aos dias normais (Hawtin et al., 1980). Segundo Saint-Clair (1972), citado por Dutta et al. (1993), genótipos de lentilha insensíveis ao fotoperíodo também já foram identificados.

Segundo Giordano et al. (1988), no centro-oeste do Brasil as áreas com altitudes acima de $800 \mathrm{~m}$ oferecem excelentes condições para o desenvolvimento dessa leguminosa em plantios realizados no mês de abril até a segunda quinzena de maio. Plantios mais tardios resultam em menor produtividade e maior risco de chuva durante a colheita. Não se encontrou, na literatura, trabalho de pesquisa sobre época de plantio de lentilha no Brasil.

O objetivo desta pesquisa foi estudar o efeito de épocas de plantio sobre a cultura da lentilha de ciclo de vida precoce, em quatro regiões de Minas Gerais.

\section{MATERIAL E MÉTODOS}

Foram conduzidos quatro ensaios em estações experimentais da Empresa de Pesquisa Agropecuária de Minas Gerais (Epamig), localizadas nos seguintes municípios e regiões de Minas Gerais: Patos de Minas (Alto Paranaíba), Uberaba (Triângulo), Janaúba (Norte) e Leopoldina (Zona da Mata). Ademais, foi conduzido outro ensaio em Viçosa (Zona da Mata), em área pertencente à Universidade Federal de Viçosa. A altitude dos locais onde os experimentos foram conduzidos é de 896, 743, 516, 220 e 640 m, respectivamente. As temperaturas máximas e mínimas (médias e absolutas) que ocorreram durante a condução dos ensaios em Patos de Minas, Uberaba, Viçosa e Janaúba são apresentadas na Tabela 1. Em Viçosa, o estudo foi realizado em 1988; em Patos de Minas, Uberaba e Leopoldina, em 1994; e em Janaúba, em 1995. O intervalo entre um plantio e outro foi de, aproximadamente, 20 dias.

Foi utilizado o delineamento em blocos ao acaso, com quatro repetições. Os resultados de cada ensaio foram analisados separadamente. Em Viçosa, cada parcela constou de cinco fileiras de $4 \mathrm{~m}$ de comprimento, com espaçamento de $40 \mathrm{~cm}$, com 30 sementes por metro da cultivar Precoz. $\mathrm{Na}$ colheita, foram eliminadas as duas fileiras laterais mais $20 \mathrm{~cm}$ das cabeceiras das fileiras centrais. Portanto, a área útil foi de 4,32 $\mathrm{m}^{2}$. Nos outros locais, cada parcela constou de quatro fileiras de $5 \mathrm{~m}$ de comprimento, com espaçamento de $30 \mathrm{~cm}$, com 50 sementes por metro da cultivar Silvina; a área útil compreendeu as duas fileiras centrais, sem $0,5 \mathrm{~m}$ de cada cabeceira $\left(2,4 \mathrm{~m}^{2}\right)$.

O solo foi preparado com aração e gradagens, e logo em seguida fez-se o plantio da primeira época. Nas épocas de plantio subseqüientes, o preparo do solo foi realizado novamente, mas com enxadão ou enxada rotativa. Quanto à adubação de plantio, foram utilizados, em Janaúba, $1.000 \mathrm{~kg} / \mathrm{ha}$ do formulado 4-14-8; em Patos de Minas, $500 \mathrm{~kg} / \mathrm{ha}$ do formulado 4-20-20; nos outros locais, $600 \mathrm{ou} 700 \mathrm{~kg} / \mathrm{ha}$ do 4-14-8. Em todos ensaios foi feita, em torno de 30 dias após a semeadura, a adubação de cobertura com sulfato de amônio: 300 kg/ha, em Viçosa, e $400 \mathrm{~kg} / \mathrm{ha}$, nos outros locais.

Em Janaúba, foi distribuído no sulco de plantio o inseticida-nematicida granulado carbofuran, na dose de $20 \mathrm{~kg} / \mathrm{ha}$. Após a semeadura, uma calda do fungicida benomyl $(0,5 \mathrm{~kg} / \mathrm{ha})$ foi pulverizada sobre as sementes. Entre 25 e 70 dias após a emergência da cultura, foram realizadas quatro pulverizações com o inseticida malathion (1,5 L/ha) misturado ao fungicida cerconil (2 L/ha). Nos outros ensaios, não foram utilizados defensivos químicos. Os ensaios foram irrigados semanalmente, com base na evapotranspiração local, descontando-se a chuva do 
período. O controle de plantas daninhas foi feito com sacho durante a fase inicial de desenvolvimento das plantas e, se necessário, manualmente, quando as plantas já estavam bem desenvolvidas.

Foram tomados os seguintes dados em pelo menos um dos ensaios: data de emergência, estande inicial, data de início e de final da floração, altura das plantas, intensidade de oídio, estande final, data de colheita, rendimento total e peso de 100 sementes. $O$ estande inicial foi avaliado na área total da parcela. A data de início da floração foi anotada quando $50 \%$ das plantas da parcela tinham pelo menos uma flor aberta, e o final da floração, quando $50 \%$ das plantas não tinham mais flor. A altura das plantas foi tomada na fase de vageamento, medindo-se a distância entre a superfície do solo e a parte mais alta de cinco plantas tomadas ao acaso, por parcela. A intensidade de oídio foi avaliada com base na seguinte escala arbitrária: $1=$ sem sintoma da doença, $3=$ leve, $5=$ moderada, $7=$ severa e $9=$ muito severa. Os dados de estande, altura das plantas, rendimento e peso de 100 sementes foram submetidos à análise de variância. Para a comparação entre médias foi utilizado o teste de Tukey, a 5\% de probabilidade.

\section{RESULTADOS E DISCUSSÃO}

\section{Ensaio de Viçosa}

O estande final médio foi de 394 mil plantas/ha (170 plantas/4,32 $\mathrm{m}^{2}$ ) (Tabela 2), população abaixo da recomendada por Giordano et al. (1988) para a cultivar Precoz: cerca de dois milhões de plantas/ha. No entanto, segundo Manara et al. (1992), o rendimento da lentilha é bastante estável numa ampla faixa de variação da densidade populacional. Com o plantio em meados de março, observou-se o menor estande, que só diferiu significativamente do verificado nas duas últimas épocas de plantio.

A lentilha emergiu entre seis e dez dias após o plantio (Tabela 2). O tempo relativamente longo para emergir, quando o plantio foi feito em 30/3, deveu-se ao atraso da irrigação após o plantio. $\mathrm{O}$ número de dias para o início do florescimento aumentou à medida que as temperaturas diminuíram (Tabela 1) e os

TABELA 1. Temperaturas $\left({ }^{\circ} \mathrm{C}\right)$ médias máximas e mínimas e temperaturas absolutas máximas e mínimas durante o período de condução dos ensaios em Patos de Minas, Uberaba, Viçosa e Janaúba.

\begin{tabular}{|c|c|c|c|c|c|c|c|c|c|}
\hline Temperatura & Fevereiro & Março & Abril & Maio & Junho & Julho & Agosto & Setembro & Outubro \\
\hline & \multicolumn{9}{|c|}{ Patos de Minas (1994) } \\
\hline Máxima média & 31,1 & 27,6 & 28,2 & 27,6 & 25,9 & 25,7 & 28,8 & 31,2 & - \\
\hline Mínima média & 18,9 & 18,5 & 17,2 & 16,0 & 12,9 & 12,8 & 13,7 & 17,0 & - \\
\hline Máxima absoluta & 33,5 & 30,5 & 29,5 & 29,5 & 28,5 & 27,9 & 30,1 & 32,9 & - \\
\hline \multirow{2}{*}{ Mínima absoluta } & 17,3 & 16,7 & 14,5 & 13,3 & 9,9 & 3,5 & 9,6 & 14,4 & - \\
\hline & \multicolumn{9}{|c|}{ Uberaba (1994) } \\
\hline Máxima média & 31,1 & 28,2 & 29,0 & 28,3 & 26,7 & 26,9 & 30,0 & 33,1 & - \\
\hline Mínima média & 19,0 & 18,3 & 16,5 & 14,9 & 11,9 & 11,8 & 12,4 & 16,4 & - \\
\hline Máxima absoluta & 35,0 & 31,0 & 31,0 & 31,0 & 29,0 & 31,0 & 34,0 & 36,0 & - \\
\hline \multirow[t]{2}{*}{ Mínima absoluta } & 17,4 & 15,8 & 10,8 & 11,0 & $-0,2$ & $-2,0$ & 4,3 & 10,4 & - \\
\hline & \multicolumn{9}{|c|}{ Viçosa (1988) } \\
\hline Máxima média & - & 28,8 & 27,1 & 26,2 & 23,1 & 23,0 & 25,1 & 27,7 & - \\
\hline Mínima média & - & 17,6 & 17,8 & 15,3 & 11,1 & 12,1 & 10,6 & 13,9 & - \\
\hline Máxima absoluta & - & 30,9 & 31,4 & 29,5 & 29,0 & 26,2 & 30,3 & 33,2 & - \\
\hline \multirow[t]{2}{*}{ Mínima absoluta } & - & 14,0 & 14,4 & 11,6 & 5,5 & 5,0 & 5,0 & 6,8 & - \\
\hline & \multicolumn{9}{|c|}{ Janaúba (1995) } \\
\hline Máxima média & - & - & - & 32,5 & 30,2 & 30,0 & 31,3 & 32,7 & 33,9 \\
\hline Mínima média & - & - & - & 20,7 & 17,0 & 18,2 & 17,4 & 19,4 & 20,5 \\
\hline Máxima absoluta & - & - & - & 35,6 & 33,2 & 33,8 & 34,6 & 38,4 & 38,2 \\
\hline Mínima absoluta & - & - & - & 17,4 & 10,4 & 12,4 & 13,2 & 15,8 & 17,2 \\
\hline
\end{tabular}


TABELA 2. Resultados médios do ensaio de época de plantio de lentilha conduzido em Viçosa, em 1988 .

\begin{tabular}{lcccccc}
\hline $\begin{array}{l}\text { Data de } \\
\text { plantio }\end{array}$ & $\begin{array}{c}\text { Estande final } \\
\left(4,32 \mathrm{~m}^{2}\right)\end{array}$ & $\begin{array}{c}\text { Plantio à } \\
\text { emergência } \\
\text { (dias) }\end{array}$ & $\begin{array}{c}\text { Emergência à } \\
\text { floração } \\
\text { (dias) }\end{array}$ & $\begin{array}{c}\text { Período } \\
\text { reprodutivo } \\
\text { (dias) }\end{array}$ & $\begin{array}{c}\text { Rendimento de } \\
\text { grãos } \\
(\mathrm{kg} / \mathrm{ha})\end{array}$ & $\begin{array}{c}\text { Peso de } 100 \\
\text { sementes } \\
(\mathrm{g})\end{array}$ \\
\hline $15 / 3$ & $137 \mathrm{~b}$ & 6 & 29 & 63 & $659 \mathrm{ab}$ & $5,2 \mathrm{a}$ \\
$30 / 3$ & $180 \mathrm{ab}$ & 10 & 28 & 75 & $756 \mathrm{a}$ & $4,7 \mathrm{ab}$ \\
$15 / 4$ & $147 \mathrm{ab}$ & 6 & 29 & 80 & $471 \mathrm{ab}$ & $4,8 \mathrm{ab}$ \\
$30 / 4$ & $180 \mathrm{ab}$ & 7 & 38 & 66 & $290 \mathrm{~b}$ & $3,3 \mathrm{c}$ \\
$15 / 5$ & $188 \mathrm{a}$ & 7 & 41 & 59 & $459 \mathrm{ab}$ & $4,2 \mathrm{~b}$ \\
$30 / 5$ & $188 \mathrm{a}$ & 8 & 44 & 55 & $863 \mathrm{a}$ & $4,4 \mathrm{~b}$ \\
\hline Média & 170,0 & 7,33 & 34,8 & 66,3 & 583,0 & 4,43 \\
CV $(\%)$ & 12,9 & & & & 25,8 & 7,4 \\
\hline
\end{tabular}

'Médias na vertical seguidas da mesma letra não apresentam diferença significativa, pelo teste de Tukey a 5\%.

Número de dias entre o início da floração e a maturação de colheita.

dias tornavam-se mais curtos (de 12,2 horas em março para 10,9 horas em junho), variando entre 28 e 44. Na Argentina, trabalhando com a cultivar Precoz, Gray \& Delgado (1989) verificaram, em estudo conduzido na latitude $24^{\circ} 54^{\prime} \mathrm{S}$, que o encurtamento do período vegetativo coincidiu com o aumento progressivo da temperatura média e do fotoperíodo. $\mathrm{O}$ período reprodutivo mais longo ocorreu quando o plantio foi feito em $15 / 4$, provavelmente por ter coincidido com o período mais frio do ano (20/5 a 8/8). Da emergência à colheita, a lentilha demorou entre $92 \mathrm{e}$ 109 dias.

Os maiores rendimentos médios foram alcançados quando o plantio foi realizado em 30/5 e em 30/3, mas essas médias só diferiram significativamente das do plantio realizado em 30/4 (290 kg/ha). Uma das razões deste baixo rendimento foi o baixo peso das sementes colhidas (Tabela 2). É possível que isso seja resultado do período frio que ocorreu na segunda quinzena de julho, quando as sementes estavam se desenvolvendo. Entre 13 de julho e 4 de agosto houve 20 dias com temperaturas inferiores a $10^{\circ} \mathrm{C}$. O maior peso de 100 sementes foi verificado com o plantio realizado em 15/3 (5,2 g), média que superou significativamente as verificadas nas três últimas épocas de plantio. Isso parece indicar que temperaturas mais amenas durante o período reprodutivo da lentilha favorecem o peso das sementes, e, conseqüentemente, o seu rendimento.

\section{Ensaio de Leopoldina}

O estande inicial médio foi de $419 \mathrm{mil}$ plantas/ha (Tabela 3). O maior estande foi verificado com o plantio em $27 / 5$, que diferiu significativamente em relação aos plantios realizados em 7/4 e 28/4. Em Viçosa, local mais frio que Leopoldina, não houve diferença entre os estandes finais nas semeaduras feitas em maio e abril.

A emergência deu-se com seis ou sete dias (Tabela 3). O número médio de dias para iniciar o florescimento da Silvina foi superior ao da Precoz em Viçosa (Tabela 2). O início e o final da floração foram mais longos quando o plantio foi feito em 28/4. A duração da floração variou de 17 a 21 dias. O período reprodutivo da lentilha plantada em 7/4 foi relativamente longo (63 dias), tempo igual ao verificado em Viçosa com o plantio em 15/3. É possível que as altas temperaturas que normalmente ocorrem em Leopoldina no mês de agosto tenham sido a causa do encurtamento do período reprodutivo da lentilha plantada nas três últimas épocas. Tal fato, no entanto, não teve influência negativa na produtividade, visto que o maior rendimento $(1.644 \mathrm{~kg} / \mathrm{ha})$ foi obtido com o plantio realizado em $27 / 5$. Esse rendimento, superior à média alcançada no Canadá (FAO Production Yearbook, 1995), diferiu significativamente dos alcançados nas duas primeiras épocas de plantio. A lentilha plantada no início de abril produziu sementes mais pesadas que aquela plantada mais tarde, resultado semelhante ao verificado em Viçosa. 
TABELA 3. Resultados médios do ensaio de época de plantio de lentilha conduzido em Leopoldina, em $1994^{1}$.

\begin{tabular}{|c|c|c|c|c|c|c|c|}
\hline $\begin{array}{l}\text { Data de } \\
\text { plantio }\end{array}$ & $\begin{array}{l}\text { Estande } \\
\text { inicial } \\
\left(6 \mathrm{~m}^{2}\right)\end{array}$ & $\begin{array}{c}\text { Plantio à } \\
\text { emergência } \\
\text { (dias) }\end{array}$ & $\begin{array}{l}\text { Emergência } \\
\text { à floração } \\
\text { (dias) }\end{array}$ & $\begin{array}{c}\text { Emergência } \\
\text { ao final da } \\
\text { floração (dias) }\end{array}$ & $\begin{array}{l}\text { Período } \\
\text { reprodutivo } \\
\quad(\text { dias })\end{array}$ & $\begin{array}{c}\text { Rendimento } \\
\text { de grãos } \\
\text { (kg/ha) }\end{array}$ & $\begin{array}{c}\text { Peso de } 100 \\
\text { sementes } \\
(\mathrm{g})\end{array}$ \\
\hline $07 / 4$ & $202 b$ & 7 & 46 & 67 & 63 & $1.088 \mathrm{~b}$ & $7,8 \mathrm{a}$ \\
\hline $28 / 4$ & $210 b$ & 6 & 65 & 86 & 35 & $1.073 \mathrm{~b}$ & $6,4 b$ \\
\hline $27 / 5$ & $329 a$ & 7 & 60 & 77 & 35 & $1.644 \mathrm{a}$ & $6,3 b$ \\
\hline $10 / 6$ & $265 \mathrm{ab}$ & 7 & 56 & 76 & 41 & $1.394 \mathrm{ab}$ & $6,5 b$ \\
\hline Média & 251,6 & 6,75 & 56,7 & 76,5 & 43,5 & 1.300 & 6,77 \\
\hline $\mathrm{CV}(\%)$ & 13,2 & & & & & 15,8 & 5,8 \\
\hline
\end{tabular}

Médias na vertical seguidas da mesma letra não apresentam diferença significativa, pelo teste de Tukey a 5\%.

\section{Ensaio de Uberaba}

O estande inicial médio de 520 mil plantas/ha (Tabela 4) foi superior ao de Leopoldina. Os estandes mais altos foram verificados nos plantios realizados a partir de 20/4. Um dos fatores responsáveis pelos menores estandes iniciais, nas três primeiras épocas de plantio, foi a maior incidência de fungos de solo.

O número de dias necessários para a lentilha emergir variou de 4 a 13 (Tabela 4). Problemas relacionados a déficit hídrico devem ter sido a causa da demora para a emergência nos plantios feitos em 17/2, $10 / 3$ e 30/3. As temperaturas relativamente altas que ocorreram durante esse período não devem ter sido a causa da demora para a emergência, pois, segundo Ellis \& Barrett (1994), entre $5^{\circ} \mathrm{Ce} 25^{\circ} \mathrm{C}$, as temperaturas mais altas aumentam a velocidade de germinação da lentilha. Ademais, em Viçosa, a emergência deuse com seis dias quando a leguminosa foi semeada em $15 / 3$. O número de dias da emergência à floração apresentou a mesma tendência verificada em Viçosa: o período vegetativo foi mais longo nos plantios feitos a partir do fim de abril. Viçosa e Uberaba têm clima mais ameno que o de Leopoldina. A duração da floração foi mais longa quando o plantio foi realizado em 30/3 (29 dias), e mais curta, nos plantios em 17/2 e 1/6. Nesses dois plantios, a coincidência do período de floração com temperaturas relativamente altas (Tabela 1) deve ter sido o fator responsável pelo encurtamento da duração de floração para 17 dias. O período reprodutivo aumentou sobremaneira quando o plantio foi feito em 30/3 e 20/4 (acima de 70 dias). Resultado semelhante foi observado em
Viçosa. Da emergência à colheita, a lentilha demorou entre 83 e 114 dias. O tempo médio para a colheita dos ensaios de Viçosa, Leopoldina e Uberaba foi semelhante: em torno de 100 dias (Tabelas 2, 3 e 4).

O maior rendimento foi alcançado quando o plantio foi feito em $12 / 5(1.495 \mathrm{~kg} / \mathrm{ha})$. O plantio em maio também proporcionou o maior rendimento em Viçosa e em Leopoldina. Diferentemente dos ensaios anteriores, não houve diferença significativa entre as médias do peso de 100 sementes. As temperaturas mais elevadas em Uberaba nos meses de julho, agosto e setembro, comparadas às de Viçosa (Tabela 1), podem ter favorecido o desenvolvimento das sementes nos plantios realizados em 20/4, 12/5 e 1/6.

\section{Ensaio de Patos de Minas}

O estande inicial médio foi de 1.154 mil plantas/ha (Tabela 5). Quando o plantio foi realizado em 30/3, o estande atingiu 1.605 mil plantas/ha. Este estande está próximo do recomendado por Giordano et al. (1988) quanto ao espaçamento entre fileiras de $20 \mathrm{~cm}$. Semelhantemente ao que aconteceu em Uberaba, o estande mais baixo ocorreu com o plantio em 17/2. A temperatura média de fevereiro nesses dois locais (Tabela 1) estava acima da considerada ótima $\left(18-21^{\circ} \mathrm{C}\right)$ para a germinação das sementes de lentilha, segundo Duke (1983).

Não foi anotada a data de emergência neste ensaio. Em média, foi de 53,2 o número de dias do plantio à floração (Tabela 5), semelhante ao de Uberaba, se se considerar oito dias como o tempo médio para as plantas emergirem. A duração média 
TABELA 4. Resultados médios do ensaio de época de plantio de lentilha conduzido em Uberaba, em 1994 1.

\begin{tabular}{|c|c|c|c|c|c|c|c|}
\hline $\begin{array}{l}\text { Data de } \\
\text { plantio }\end{array}$ & $\begin{array}{l}\text { Estande } \\
\text { inicial } \\
\left(6 \mathrm{~m}^{2}\right)\end{array}$ & $\begin{array}{c}\text { Plantio à } \\
\text { emergência } \\
\text { (dias) }\end{array}$ & $\begin{array}{c}\text { Emergência à } \\
\text { floração } \\
\text { (dias) }\end{array}$ & $\begin{array}{l}\text { Emergência ao } \\
\text { final da } \\
\text { floração (dias) }\end{array}$ & $\begin{array}{l}\text { Período } \\
\text { reprodutivo } \\
\quad \text { (dias) }\end{array}$ & $\begin{array}{c}\text { Rendimento } \\
\text { de grãos } \\
\text { (kg/ha) }\end{array}$ & $\begin{array}{c}\text { Peso de } 100 \\
\text { sementes } \\
(\mathrm{g})\end{array}$ \\
\hline $17 / 2$ & $216 \mathrm{c}$ & 13 & 37 & 54 & 46 & $86 c$ & - \\
\hline $10 / 3$ & $296 b c$ & 8 & 41 & 62 & 42 & $138 \mathrm{c}$ & 5,0 \\
\hline $30 / 3$ & $224 c$ & 9 & 39 & 68 & 72 & $50 c$ & 4,7 \\
\hline $20 / 4$ & $374 \mathrm{ab}$ & 4 & 43 & 63 & 71 & $354 b c$ & 5,2 \\
\hline $12 / 5$ & $368 \mathrm{ab}$ & 5 & 51 & 69 & 54 & $1495 \mathrm{a}$ & 5,7 \\
\hline $01 / 6$ & $396 a$ & 7 & 60 & 77 & 43 & $820 b$ & 4,5 \\
\hline Média & 312 & 7,67 & 45,2 & 65,5 & 54,7 & 484,5 & 5,01 \\
\hline $\mathrm{CV}(\%)$ & 12,5 & & & & & 38,8 & 16,5 \\
\hline
\end{tabular}

${ }^{1}$ Médias na vertical seguidas da mesma letra não apresentam diferença significativa, pelo teste de Tukey a 5\%.

TABELA 5. Resultados médios do ensaio de época de plantio de lentilha conduzido em Patos de Minas, em $1994^{1}$.

\begin{tabular}{|c|c|c|c|c|c|c|}
\hline $\begin{array}{l}\text { Data de } \\
\text { plantio }\end{array}$ & $\begin{array}{l}\text { Estande } \\
\text { inicial } \\
\left(6 \mathrm{~m}^{2}\right)\end{array}$ & $\begin{array}{c}\text { Plantio à } \\
\text { floração } \\
\text { (dias) }\end{array}$ & $\begin{array}{c}\text { Plantio ao final } \\
\text { da floração } \\
\text { (dias) }\end{array}$ & $\begin{array}{l}\text { Período } \\
\text { reprodutivo } \\
\text { (dias) }\end{array}$ & $\begin{array}{c}\text { Rendimento } \\
\text { de grãos } \\
(\mathrm{kg} / \mathrm{ha})\end{array}$ & $\begin{array}{c}\text { Intensidade } \\
\text { de oídio }\end{array}$ \\
\hline $17 / 2$ & $423 d$ & 55 & 76 & 48 & $500 \mathrm{~b}$ & 1 \\
\hline $10 / 3$ & $682 b c$ & 42 & 69 & 61 & $536 b$ & 3 \\
\hline $30 / 3$ & $963 a$ & 55 & 81 & 59 & $567 \mathrm{~b}$ & 3 \\
\hline $20 / 4$ & $774 \mathrm{ab}$ & 56 & 81 & 62 & $755 \mathrm{~b}$ & 3 \\
\hline $12 / 5$ & $821 \mathrm{ab}$ & 54 & 77 & 66 & $1557 \mathrm{a}$ & 1 \\
\hline $02 / 6$ & $491 \mathrm{~cd}$ & 57 & 72 & 54 & $807 \mathrm{~b}$ & 1 \\
\hline Média & 692,3 & 53,2 & 76,0 & 58,4 & 787,2 & 2 \\
\hline $\mathrm{CV}(\%)$ & 14,0 & & & & 40,4 & \\
\hline
\end{tabular}

Médias na vertical seguidas da mesma letra não apresentam diferença significativa, pelo teste de Tukey a 5\%.

1: ausência da doença; 3 : ataque leve de doença.

da floração foi um pouco mais longa que a verificada em Uberaba. A variação entre a maior e a menor média no período de 10/3 a 12/5 foi de quatro dias, enquanto em Uberaba, ela foi de 11 dias. Uberaba apresentou temperaturas máximas e mínimas (Tabela 1) mais extremas que as de Patos de Minas. Esse fato pode ser uma das razões da diferença entre a duração de floração e, possivelmente, também da diferença entre as médias do período reprodutivo verificadas nos dois locais. O ciclo de vida médio da lentilha foi de 111,5 dias.

De maneira semelhante ao verificado em Uberaba, o maior rendimento $(1.557 \mathrm{~kg} / \mathrm{ha})$ foi alcançado quan- do o plantio foi feito em 12/5 (Tabela 5). Aparentemente, as condições climáticas (Tabela 1) de Patos de Minas foram mais favoráveis que as de Uberaba quanto ao plantio da lentilha entre 17/2 e 20/4 (Tabelas 4 e 5). As plantas provenientes da lentilha plantada entre $10 / 3$ e 20/4 apresentaram sintomas leves de oídio (Erysiphe sp.), doença que não foi observada nos ensaios anteriores.

\section{Ensaio de Janaúba}

O estande inicial médio foi de $352 \mathrm{mil} \mathrm{plantas/ha}$ (Tabela 6). As plantas atingiram maior altura $(51,3 \mathrm{~cm})$ 
TABELA 6. Resultados médios do ensaio de época de plantio de lentilha conduzido em Janaúba, em $1995^{1}$.

\begin{tabular}{lcccccc}
\hline $\begin{array}{l}\text { Data de } \\
\text { plantio }\end{array}$ & $\begin{array}{c}\text { Estande } \\
\text { inicial } \\
\left(6 \mathrm{~m}^{2}\right)\end{array}$ & $\begin{array}{c}\text { Altura de } \\
\text { planta } \\
(\mathrm{cm})\end{array}$ & $\begin{array}{c}\text { Plantio à } \\
\text { floração } \\
(\text { dias })\end{array}$ & $\begin{array}{c}\text { Período } \\
\text { reprodutivo } \\
(\text { dias })\end{array}$ & $\begin{array}{c}\text { Rendimento } \\
\text { de grãos } \\
(\mathrm{kg} / \mathrm{ha})\end{array}$ & $\begin{array}{c}\text { Peso de } \\
100 \text { sementes } \\
(\mathrm{g})\end{array}$ \\
\hline $16 / 5$ & 205 & $51,3 \mathrm{a}$ & 50 & 58 & $1416 \mathrm{a}$ & $5,50 \mathrm{a}$ \\
$02 / 6$ & 215 & $41,0 \mathrm{~b}$ & 51 & 57 & $1341 \mathrm{a}$ & $4,39 \mathrm{bc}$ \\
$22 / 6$ & 173 & $37,1 \mathrm{bc}$ & 51 & 51 & $673 \mathrm{~b}$ & $3,93 \mathrm{bc}$ \\
$13 / 7$ & 247 & $31,8 \mathrm{~d}$ & 60 & 37 & $494 \mathrm{bc}$ & $3,46 \mathrm{c}$ \\
$03 / 8$ & 215 & $33,3 \mathrm{~cd}$ & 60 & 39 & $95 \mathrm{c}$ & $4,77 \mathrm{ab}$ \\
\hline Média & 211,0 & 38,9 & 54,4 & 48,4 & 803,8 & 4,41 \\
CV $(\%)$ & 20,5 & 5,0 & & & 31,3 & 9,9 \\
\hline
\end{tabular}

${ }^{1}$ Médias na vertical seguidas da mesma letra não apresentam diferença significativa, pelo teste de Tukey a $5 \%$.

quando o plantio foi realizado em 16/5, e menor altura, nas duas últimas épocas de plantio.

O período vegetativo foi mais longo nas duas últimas épocas de plantio (Tabela 6). Porém, ocorreu o inverso em relação ao período reprodutivo. $\mathrm{O}$ maior ciclo de vida da lentilha foi verificado nas duas primeiras épocas de plantio (108 dias). O período reprodutivo curto foi o fator responsável pelo ciclo de vida inferior a 100 dias verificado nas duas últimas datas de plantio. As altas temperaturas que ocorreram a partir de setembro (Tabela 1) devem ter tido influência marcante na redução do período reprodutivo da lentilha.

O plantio realizado em 16/5 proporcionou o maior rendimento $(1.416 \mathrm{~kg} / \mathrm{ha})$, o qual não diferiu significativamente do obtido em 2/6 (Tabela 6). Em Leopoldina, local onde as temperaturas também são elevadas, a época de plantio mais adequada também se estendeu até o início de junho. Nos plantios feitos a partir de 22/6 os rendimentos foram baixos, principalmente no realizado no início de agosto. $\mathrm{O}$ plantio em 16/5 proporcionou a produção de sementes mais pesadas. Em estudo conduzido em Bangladesh com a subespécie microsperma, Dutta et al. (1993) obtiveram resultado semelhante ao deste ensaio: o decréscimo do rendimento esteve associado a uma diminuição da altura das plantas e do peso das sementes.

Neste ensaio foram feitas aplicações de inseticidas e fungicidas. Nos outros ensaios, em que não se utilizaram defensivos químicos, não foram observa- dos danos nas plantas, causados por insetos ou doenças, com exceção dos fungos de solo, observados em Uberaba (nos meses de fevereiro e março), e do oídio (intensidade leve) em Patos de Minas. Segundo Duke (1983), a lentilha é afetada seriamente por menor número de doenças que as leguminosas dos gêneros Phaseolus e Pisum.

\section{CONCLUSÕES}

1. A lentilha precoce, plantada no outono e irrigada, leva de seis a oito dias para emergir do solo.

2. Em geral, a melhor época de plantio da lentilha precoce é maio, principalmente na segunda quinzena; em Viçosa, pode ser plantada também na segunda quinzena de março; em Leopoldina e Janaúba, também no início de junho.

3. Nas melhores épocas de plantio, a lentilha leva, da emergência à floração, de 28 a 60 dias, e 92 a 112 dias, da emergência à colheita.

4. Em maio, o peso de 100 sementes da cultivar Silvina varia, em geral, de 5,5 a 6,3 gramas.

\section{AGRADECIMENTOS}

Aos técnicos agrícolas da Epamig Gercino Lopes, José Soares Ribeiro, Renato Soares de Faria e Vicente de Paulo da Costa, pela valiosa ajuda na condução dos ensaios. 


\section{REFERÊNCIAS}

BRASIL. Ministério da Fazenda. Comércio exterior do Brasil: importação. Brasília: Secretaria da Receita Federal, 1992. p.1590.

DUKE, J.A. Handbook of legumes of world economic importance. 2.ed. New York: Plenum, 1983. 345p.

DUTTA, R.K.; SHAIKH, M.A.Q.; CHOWDHURY, S.I.; MUSLIMUDDIN, M. Physiology of flowering and pod development in lentil in relation to photoperiod and temperature. Lens Newsletter, Aleppo, v.20, n.1, p.51-56, 1993.

ELLIS, R.H.; BARRETT, S. Alternating temperatures and rate of seed germination in lentil. Annals of Botany, v.74, n.5, p.519-524, 1994.

FAO PRODUCTION YEARBOOK. Roma: FAO, v.49, p.105, 1995.
GIORDANO, L. de B.; PEREIRA, W.; LOPES, J.F. Cultivo da lentilha. Brasília: Embrapa-CNPH, 1988. 3p. (Instruções Técnicas, 9).

GRAY, L.N.; DELGADO, N.C. de. Environmental variation in time to flower in lentil. Lens Newsletter, Aleppo, v.16, n.2, p.19-21, 1989.

HAWTIN, G.C.; SINGH, K.B.; SAXENA, M.C. Some recent developments in the understanding and improvement of Cicer and Lens. In: SUMMERFIELD, R.J.; BUNTING, A.H. (Eds.). Advances in legume science. Kew: Royal Botanic Gardens, 1980. p.613-623.

MANARA, W.; MANARA, N.T.F.; VEIGA, P.; TARRAGÓ, M.F.S. A cultura da lentilha. Informe Agropecuário, Belo Horizonte, v.16, n.174, p.61-70, 1992. 